\title{
Cardiac rehabilitation: the role of psychological intervention
}

Hannah McGee, PhD, Health Psychologist, Beaumont Hospital, Beaumont Road, Dublin 9, Ireland.

A coronary event has major psychological, as well as physical, consequences. The recent British Cardiac Society's Working Party Report on Cardiac Rehabilitation ${ }^{1}$ acknowledges the importance of comprehensive rehabilitation programmes incorporating a psychological input. Psychological intervention as part of cardiac rehabilitation serves two purposes: to maximise psychosocial recovery, including return to customary activities such as work and sexual relationships, and to facilitate the secondary prevention of coronary heart disease. The latter involves providing behavioural change strategies for a range of lifestyle factors from stress identification and management, through dietary, smoking and physical activity change, to increasing adherence to medication regimes.

Psychological interventions have proven successful in decreasing general morbidity in the year after coronary events ${ }^{2}$ and in reducing reinfarction-related mortality. ${ }^{3,4}$ Little is understood about the mechanisms by which psychological interventions may operate. However, a recent seminal study of intensive lifestyle modification in cardiac patients has demonstrated that it is possible to achieve regression of atherosclerosis (although the authors themselves caution that their intensive methods are unlikely to be applicable in most patient settings). ${ }^{5}$ More general discussion of the relationship between psychological factors and coronary disease is available. ${ }^{6}$ With regard to enhancement of psychosocial recovery, early work documented positive effects of exercise-only programmes on psychosocial functioning.'

However, a number of more recent controlled clinical trials have not found lasting psychosocial benefits from exercise training alone in coronary patients. ${ }^{8} \mathrm{O}$ 'Connor and colleagues, ${ }^{9}$ in a review of randomised trials of cardiac rehabilitation, compared the results of six 'exercise-only' and 15 'exercise plus other' interventions. They illustrated that the risk of cardiovascular mortality and sudden death was 'substantially lower' in the 'exercise plus other' group although they cautioned that definitive conclusions could not be drawn because of the small number of studies in the 'exercise only' category. Similarly, van Dixhoorn and colleagues have shown that exercise training combined with relaxation is associated with fewer ST segment abnormalities or cardiac events following training than is exercise training alone. ${ }^{10,11}$ The evidence overall suggests that exercise and psychological interventions may be complementary aspects of cardiac rehabilitation programmes.

Regarding psychological input on cardiac rehabilitation programmes, a recent European survey ${ }^{12}$ has demonstrated wide national variability. Where programmes exist, ${ }^{1}$ some countries maintain a more traditional exercise-based service, while others, particularly the Netherlands, Italy, Austria and Finland, have comprehensive rehabilitation programmes with substantial psychological input on cardiac rehabilitation teams. A variety of professionals are involved including psychologists, counsellors, social workers and nurse coordinators. Maes, ${ }^{12}$ focusing on non-medical personnel, estimates rates of three to six cardiac team psychologists per million population in these countries. Ireland currently has one fulltime psychologist post.

The one out-patient exercise-based multidisciplinary programme currently in operation in Ireland, at Beaumont Hospital, has had psychological input since its inception over a decade ago. The 10-week programme involves a weekly one-hour small group session with a psychologist. Spouses or other family members are included twice in the programme, in keeping with international trends and with research evidence on the contribution of spouses to such programmes. ${ }^{13}$ Stress management audio-tapes, based on progressive muscle relaxation and made specifically for the Beaumont Programme, are available to patients as part of this service.

In any countrywide expansion of cardiac rehabilitation services, the contribution of psychologists may be achieved through cooperation within or across the programme structures of the health boards. Thus, as with the Working Party Report's ${ }^{1}$ suggestions about the resources required for cardiac rehabilitation generally, the personnel may already be available regionally to provide psychological services if cardiac rehabilitation is adopted and prioritised as an issue for consideration by the Irish health authorities.

For the future, attention is increasingly focusing on particular patient sub-groups within the cardiac rehabilitation population. ${ }^{14}$ Recent research illustrates that for an unselected group, cardiac rehabilitation may accelerate recovery rather than promote a higher level of quality of life in the

Editor-In-Chlef: Brian Lawlor (Dublin). Editors: Timothy Dinan (London), David King (Belfast). Deputy Editor: Brian O'Shea (Dublin). Associate Editors: Ken Brown (Belfast), Patricia Casey (Dublin), Anthony Clare (Dublin), Stephen Cooper (Belfast), Thomas Fahy (Galway), Michael Fitzgerald (Dublin), Michael Kelleher (Cork), Brian Leonard (Galway), Roy McClelland (Belfast), Aidan McGennis (Dublin), Ciaran O'Boyle (Dublin), Eadbhard O'Callaghan (Dublin), Art O'Connor (Dublin), Ethna O'Gorman (Belfast), lan Pullen (Edinburgh), David Sheehan (Tampa), Philip Snaith (Leeds), Hugh Staunton (Dublin), John Waddington (Dublin), Richard Williams (Calgary). Statistical Editor: Leslie Daly (Dublin). Deputy Statistical Editor: Ronan Conroy (Dublin). 
longer term. ${ }^{15}$ It is likely that many patients could benefit from minimal rehabilitation interventions, ${ }^{16}$ while others need intensive and ongoing support. For instance, poorer psychological status may itself impede the delivery of cardiac rehabilitation.

In a study of dropout from cardiac rehabilitation, dropouts could be identified with $90 \%$ specificity by pre-programme psychological assessment; those leaving the programme were initially more anxious and depressed. ${ }^{17}$ Thus early psychological assessment, and intervention where appropriate, may promote more effective use of other aspects of cardiac rehabilitation. There is already evidence of the value of cardiac rehabilitation in sub-groups such as older patients ${ }^{18}$ and those with congestive cardiac failure. ${ }^{19}$ The specific needs of such sub-groups require increased attention. The important contribution of family members, particularly spouses, in cardiac rehabilitation also requires further attention. The role of the various professionals involved in cardiac rehabilitation will be to deliver programmes tailored to the different needs of these groups.

The evaluation of cardiac rehabilitation services has moved from outcomes focused primarily on mortality and morbidity to those focusing on the quality of life of the individual patient. Evidence, as already outlined here, demonstrates the effectiveness of these services in improving quality of life. Comprehensive rehabilitation programmes have also been shown to be effective; rehabilitated patients use health services less often than controls in the year following myocardial infarction (MI) in both $\mathrm{US}^{20}$ and $\mathrm{UK}^{16}$ studies. Health services savings in the five years following MI have been calculated at $£ 6,680$ a patient in a Swedish Study. ${ }^{21}$ Despite such supportive evidence, cardiac rehabilitation services will not be available to all Irish patients in the foreseeable future in the absence of a coordinated national strategy of programme development and support. As the largest chronic disease affecting the Irish population, every effort must be made, not only in primary prevention of coronary disease, but also in optimising the rehabilitative potential of those already having coronary disease. A multidisciplinary cardiac rehabilitation approach, including psychological input, is the way forward for Irish cardiology services.
References

l. Horgan JH, Bethell H, Carson P, Davidson C, Julian D, Mayou RA, Nagle R. British Cardiac Society Working Party Report on cardiac rehabilitation. Br Heart J $1992 ; 67: 412-8$

2. Langosch W, Seer P, Brodner G, Kallinke D, Kulice B, Helm P. Behaviour therapy with coronary heart disease patients: results of a comparative study. $J$ Psychosom Res 1982; 10: 1-29.

3. Friedman H, Thoresen CE, Gill JJ, et al. Alteration of type A behaviour and its effect on cardiac recurrences in postmyocardial infarction patients: summary results of the Recurrent Coronary Prevention Project. Am Heart J 1986; 112: 653-65.

4. Frasure-Smith N, Prince R. The Ischemic Heart Disease Life Stress Monitoring Program: impact on mortality. Psychom Med 1985; 47: 431-45.

5. Ornish D, Brown SE, Schwerwitz LW, et al. Can lifestyle changes reverse coronary heart disease? Lancet 1990; 336: 129-33.

6. McGee HM, Graham T, Horgan JH, (Eds). Heart disease: the psychological challenge. Ir J Psychol 1994; 15:1.

7. Prosser G, Carson P, Comoss $P$, et al. Morale in coronary patients following an exercise programme. J Psychosom Res 1981; 25: 587-93.

8. Leon AS, Certo C, Comoss $P$ et al. Scientific evidence of the value of cardiac rehabilitation services with emphasis on patients following myocardial infarction section I: exercise conditioning component. J Cardiopulm Rehab 1990; 10: 79-87. 9. O'Connor GT, Buring JE, Yusuf S, et al. An overview of randomised trials of rehabilitation with exercise after myocardial infarction. Circulation 1989; 80:234-44 10. van Dixhoorn J, Duivenvoorden HJ, Staal HA. Physical training and relaxation therapy in cardiac rehabilitation assessed through a composite criteria for training outcome. Am Heart J 1989; 118: 545-52.

11. van Dixhoom J, Duivenvoorden HJ, Staal JA, Poolj, Verhage F. Cardiac events after myocardial infarction; possible effect of relaxation therapy. Eur Heart J 1987; 8: $1210-4$.

12. Maes S. Psychosocial aspects of cardiac rehabilitation in Europe. $\mathrm{Br} \mathrm{J}$ Clin Psychol 1992; 31: 473-83.

13. Dracup K, Meleis A, Baker K, Edlefsen P. Family-focused cardiac rehabilitation - a role supplement programme for cardiac patients and spouses. Nurs Clin North Am 1984; 19: 113-24.

14. McGee HM, Horgan JH. Cardiac rehabilitation programmes: are women less likely to attend? BMJ 1992; 305: 283-4.

15. Oldridge $N$, Guyatt $G$, Jones $N$, et al. Effects on quality of life with comprehensive rehabilitation after acute myocardial infarction. Am J Cardiol 1991; 67: $1084-9$.

16. Lewin B, Robertson IH, Cay EL, Irving JB, Campbell M. Effects of self-help post myocardial infarction rehabilitation on psychological adjustment and use of health services. Lancet 1992; 339: 1036-40.

17. Blumenthal JA, Williams RS, Wallace AG, William RB, Needles TL. Physiological and psychological variables predict compliance to prescribed exercise therapy in patients recovering from myocardial infarction. Psychosom Med 1982; 44: 519-27.

18. Siddiqui HA. Cardiac rehabilitation and elderly patients. Age \& Ageing 1992; 21: 157-9.

19. Coats AJS, Adamopoulos S, Meyer TE, Conway J, Sleight P. Effects of physical training in chronic heart failure. Lancet 1990; 335: 63-6.

20 . Oldridge N, Furlong W, Feeing D, et al. Economic evaluation of cardiac rehabilitation soon after myocardial infarction. Am J Cardiol 1993; 72: 154-61. 21. Levin L, Perk J, Hedback B. Cardiac rehabilitation - a cost analysis. J Int Med 1991; $230: 427-35$.

Original manuscript received June 21, 1993.

Final revision accepted March 15, 1994 